DOSSIÊ TEMÁTICO: Formação inicial de professores em contextos escolares e binômio teoria/prática nos estágios supervisionados

dol https://doi.org/10.22481/rpe.v16i43.7666

\title{
FORMAÇÃO INICIAL DE PROFESSORES E O ESTÁGIO SUPERVISIONADO: EXPERIÊNCIA FORMADORA?
}

\author{
INITIAL TEACHER TRAINING AND SUPERVISED INTERNSHIP: FORMATIVE \\ EXPERIENCE?
}

\begin{abstract}
FORMACIÓN INICIAL DE PROFESORES Y LA PRÁCTICA SUPERVISADA: ¿EXPERIENCIA FORMATIVA?
\end{abstract}

\begin{abstract}
Antonia Edna Brito Universidade Federal do Piauí - Brasil

Resumo: A produção científica sobre a formação professores tem sido bastante ampliada no cenário educacional brasileiro e tem indicado diferentes aspectos que merecem uma análise acurada. Dentre os aspectos que se sobressaem nessas produções elencamos questões relativas à formação inicial como locus de apropriação da cultura profissional docente e ao estágio supervisionado como importante componente formativo, que pode favorecer o desenvolvimento da reflexividade e a produção de aprendizagens sobre ensinar e ser professor. O estágio supervisionado, na perspectiva deste estudo, é compreendido como experiência formadora, como aquela que "[...] simboliza atitudes, comportamentos, pensamentos, saber-fazer, sentimentos, que caracterizam uma subjetividade e identidades (JOSSO, 2004, p. 48). Para abordar essa temática partimos das seguintes indagações: Que tipo de formação inicial atende aos interesses e necessidades formativas dos futuros professores? Como se formam os professores? Qual a importância do estágio supervisionado na formação inicial de professores, como experiência formadora?. O estudo tem como base os pressupostos da abordagem biográfica, por favorecer o autoconhecimento e a autoformação. O estudo evidencia o estágio supervisionado como experiência formadora, que afeta vivências e conhecimentos produzidos nos percursos formativos.
\end{abstract}

Palavras-chave: Formação inicial. Estágio supervisionado. Experiência formadora.

Abstract: The scientific production on teacher training has been greatly expanded in the Brazilian educational scenario and has shown different aspects that deserve an accurate analysis. Among the aspects that stand out in these productions we list issues related to initial training as a locus of appropriation of the professional teaching culture and the supervised internship as an important formative component, which can favor the development of reflexivity and production of learning about teaching and teacher. The supervised internship, in the perspective of this study, is understood as a formative experience, as one that [...] symbolizes attitudes, performances, thoughts, know-how, feelings, which characterize subjectivity and identities (JOSSO, 2004, p. 48). In order to address this theme, We based it on the following questions: What type of first formation suits the interests and formative needs of future teachers? How are teachers trained? What is the importance of the 
supervised internship in the initial teacher training, as a formative experience? This work is based on the assumptions of the biographical approach, supporting self-knowledge and self-education. The study shows the supervised internship as a formative experience, which affects experiences and knowledge produced in formative courses.

Keywords: Initial Formation. Supervised internship. Formative experience.

Resumen: La producción científica sobre la formación de profesores ha sido bastante dilatada en el escenario educativo brasileño y ha indicado diferentes aspectos que merecen un análisis riguroso. Dentro de los aspectos que sobresalen en esas producciones enumeramos cuestiones relativas a la formación inicial como lugar de apropiación de la cultura profesional docente y la práctica supervisada como importante componente formativo, que puede favorecer el desarrollo de la reflexibilidad y la producción de aprendizajes sobre enseñar a ser profesor. La práctica supervisada, en la perspectiva de este estudio, es comprendida como experiencia formativa, como aquella que "[...] simboliza actitudes, pensamientos, saber hacer, sentimientos, que caracterizan una subjetividad e identidades (JOSSO. 2004, p. 48). Para abordar esta temática partimos de las siguientes investigaciones: ¿Qué tipo de formación inicial atiende los intereses y necesidades formativas de los profesores? ¿Cómo se forman los profesores? ¿Cuál es la importancia de la práctica supervisada en la formación de los profesores, como experiencia formativa? El estudio tiene como base la presuposición del enfoque biográfico, por favorecer el auto conocimiento y la auto formación. El estudio evidencia la práctica supervisada como una experiencia formativa, que afecta vivencias y conocimientos producidos en los recorridos formativos.

Palabras clave: Formación inicial. Práctica supervisada. Experiencia formadora.

\section{À guisa de introdução}

O estágio supervisionado, na formação de professores, constitui experiência formadora? Como desenvolver o estágio supervisionado para que se configure uma experiência formadora? Considerando os questionamentos apresentados, nosso objetivo no presente texto é analisar a importância do estágio supervisionado na formação inicial de professores, como experiência formadora. Entendemos o estágio supervisionado na formação inicial de professores como um dos contextos de fabricação de suas identidades e de aprendizagens sobre a profissão docente. Considerando o objetivo do estudo, organizamos o texto em duas seções, além da introdução e da conclusão. A introdução apresenta a temática do estudo e seu desenvolvimento neste artigo. Na seção primeira analisamos a formação inicial de professores no contexto brasileiro, a partir de seu delineamento teórico e metodológico. A seção dois aborda a problemática do estágio supervisionado na formação de professores, refletindo sobre seus limites e possibilidades como experiência formadora. $\mathrm{Na}$ seção conclusiva enfatizamos as possibilidades do estágio supervisionado como experiência 
significativa que pode afetar os sujeitos envolvidos, ampliando suas aprendizagens, seus conhecimentos e suas práticas.

\section{Formação professores e estágio supervisionado: aprender a profissão docente}

A formação de professores tem sido ressignificada ao longo tempo no contexto brasileiro em virtude das mudanças que ocorrem na sociedade nas diversas áreas, resultando na fabricação de diferentes identidades docentes. Sobre esse aspecto consideramos os estudos de Sheibe (2008) referente aos aspectos históricos da formação de professores no contexto brasileiro. A autora faz referências, entre outros aspectos, à trajetória de negociações, envolvendo diferentes entidades e atores empenhados nas análises das políticas de formação de professores no Brasil. Refere-se, também, à carga horária dos cursos de formação, ao estágio supervisionado, a unidade teoria-prática e as inter-relações entre disciplinas pedagógicas e de conteúdos específicos.

As ideias da autora reforçam nossas convicções sobre a necessidade de as políticas de formação de professores, inicial ou continuada, serem instituídas como políticas de Estado e, não meramente como políticas de governo, haja vista que, se forem implantadas como políticas de governo, testemunharemos a descontinuidade dessas políticas, sem que tenham sido objeto de uma avaliação crítica e criteriosa. No que concerne à formação inicial, particularmente para os anos iniciais do ensino fundamental, vivenciamos muitas discussões e muitas mudanças para alinhar a formação de professores aos preceitos legais e ás demandas da sociedade e da educação e dos professores.

Moreira, Flores e Oliveira (2017, p.7) reconhecem que a formação de professores “[...] tem sido objeto de debate, nem sempre consensual, sobre suas finalidades, o seu currículo, os seus modos de organização e o seu impacto na aprendizagem profissional dos docentes". Concordamos com as autoras e nos reportamos ao caso específico da formação de professores para os anos iniciais do ensino fundamental, cujo currículo e finalidades têm sido constantemente objeto de revisões e de reformulações. Considerando o cenário de ocorrência da formação desses professores, nos parece pertinente questionar: $O$ que os futuros professores precisam aprender sobre a profissão docente? Que experiências formativas podem potencializar suas aprendizagens profissionais? De que modo o estágio supervisionado pode colaborar com as aprendizagens docentes? 
Para responder às indagações apresentadas precisamos esclarecer nosso entendimento sobre a formação de professores. O primeiro aspecto a destacar diz respeito às finalidades dos processos formativos de professores, focalizando particularmente a formação inicial. Nessa modalidade de formação o que se espera é que os futuros professores tenham acesso à cultura profissional docente, compreendida como um conjunto de experiências e de conhecimentos inerentes à profissão professor.

Ou seja, entendemos que para ensinar é necessário conhecimento especializado, o que, segundo Imbernón (2009), tem a ver com o fato de a profissão docente demandar um conhecimento pedagógico específico, bem como por requerer que os professores tenham conhecimentos polivalentes. Na perspectiva de análise do autor, o conhecimento pedagógico constitui um diferencial na prática dos professores, é legitimado em suas ações, no cotidiano da sala de aula e possui natureza dinâmica por ser elaborado/reelaborado diante das circunstâncias e contingências de desenvolvimento do trabalho docente.

A alusão que fazemos aos estudos de Imbernón (2009) serve para ratificar nosso entendimento sobre a natureza da prática docente, que constitui atividade sistemática e intencional, cuja finalidade é a socialização e a produção de conhecimentos. Considerando esse entendimento sobre a prática docente, ressaltamos que ao refletirmos sobre a formação de professores precisamos lembrar as singularidades da profissão professor e, com esse intuito, retomamos uma das questões apresentadas nas reflexões empreendidas neste texto, em relação ao que os futuros professores precisam aprender sobre a profissão docente.

A formação inicial, na acepção deste estudo, representa um espaço/tempo de aprendizagens docentes, consubstanciadas em conhecimentos plurais, na unidade teoriaprática, na reflexão crítica, entre outros aspectos igualmente importantes. Significa que formar professores implica ter como referência as condições objetivas e subjetivas das práticas docentes, cuja natureza complexa e contingencial exige que mobilizem, articulem e produzam conhecimentos. Significa, também, considerar que o ensino se dá no contexto de uma profissão, balizada por conhecimentos específicos, relativos ao saber (conhecimento do conteúdo), ao saber fazer (conhecimentos pedagógicos) e ao saber ser (dimensão ética, social, e política do ensino).

No âmbito dessa formação, os futuros professores desejam aprender sobre a profissão, especialmente desejam aprender como ensinar. Essas expectativas relacionadas ao desejo de aprender a ensinar nem sempre explicitam o reconhecimento da unidade teoria-prática e, por esse motivo, é comum no discurso dos futuros professores a referência a ideia de que, na 
prática, a teoria é outra coisa. Diante dessa realidade cabe-nos refletir sobre como formamos (e sobre como se formam) os futuros professores e sobre como tecemos as relações com o conhecimento, no contexto acadêmico da formação inicial de professores, na perspectiva de elucidar que não há um modelo ideal de prática e, tampouco existe prática sem uma teoria subjacente.

Os estudos de Formosinho (2009), embora não abordem a realidade brasileira, apresentam reflexões que servem de referência para uma análise da formação de professores no Brasil. Segundo o autor, a academização dos processos formativos de professores tem alguns efeitos que merecem uma análise crítica. Como decorrência disso, nos permite inferir que a ênfase na formação teórica, distanciada da realidade das práticas materializadas nas escolas, constitui fator que fragiliza a formação de professores. Suas ideias reforçam a dimensão profissionalizante que a formação precisa assumir, tendo em vista que "[...] a docência é uma atividade de serviço, que o professor é, para além de especialista numa área do saber, também um profissional de ajuda, um agente de desenvolvimento humano" (FORMOSINHO, 2009, p. 94). A docência, portanto, é realçada como atividade que não se restringe á transmissão de conhecimentos. Pelo contrário, é informada como atividade que associa a mediação de conhecimentos às dinâmicas de formação e de desenvolvimento pessoal e profissional e, sendo assim, configura-se uma atividade baseada em diferentes tipos de conhecimentos, sintonizados com a natureza multifacetada da prática docente.

A partir das reflexões que desenvolvemos neste estudo questionamos, também, a respeito de quais experiências formativas podem potencializar as aprendizagens profissionais dos futuros professores. Em primeiro lugar, reconhecemos que há uma especificidade na formação de professores, por se tratar de um processo formativo no qual os envolvidos (futuros professores) possuem conhecimentos pré-profissionais sobre ser professor, sobre o ensino e a escola, decorrentes de suas histórias escolares na educação básica. O conhecimento pré-profissional pode subsidiar as relações dos futuros professores com a base de conhecimentos profissionais dos processos formativos. Formosinho (2009) comenta a respeito da especificidade da formação de professores recomendando que seus conhecimentos prévios, relativos à escola e suas práticas, tenham visibilidade em seus percursos de formação profissional, como recurso para explicitar a unidade teoria-prática na socialização e a produção de conhecimentos profissionais docentes no âmbito da formação inicial.

Em segundo lugar, postulamos que os efeitos da formação de professores não dependem apenas das ações dos formadores e do desenvolvimento do currículo da formação. 
Esses aspectos são muito importantes, mas é igualmente importante o modo como os futuros professores se implicam em seus processos formativos, refletindo sobre o que aprendem, o que precisam aprender e sobre seus limites e suas possibilidades. O desejo e a vontade de aprender representam fatores essenciais nos processos formativos dos professores e em suas aprendizagens docentes. O que desejamos realçar é a importância do papel dos formadores e a importância do protagonismo dos futuros professores em seu processo de formação.

E, em terceiro lugar, as experiências na formação de professores tem nos revelado que nem sempre o conhecimento socializado nas disciplinas é atrativo ou parece significativo para os futuros professores. No caso, específico do curso de Pedagogia, locus de nossa prática docente, temos sentido a necessidade de mobilização dos estudantes para que se envolvam efetivamente na formação, para que assumam responsabilidades com a autoformação. A ideia de autoformação sugere que o estudante assuma o poder de sua formação, assuma o poder de deliberar sobre como e por que se se implicar em seus processos formativos, conforme Pineau (2010). Ou seja, no caso de futuros professores, que possam gerir a formação, conscientes de seus papeis e sobre os determinantes sociais que os afetam e afetam, também, os processos formativos.

As reflexões sobre os processos de formação de professores têm mostrado que os professores e sua formação não podem ser analisados sem levar em conta a realidade, “[...] de forma isolada, como se fossem algo independente de outros agentes, poderes e decisões que operam no seio de determinados círculos ideológicos, sociais, políticos e escolares mais amplos" (ESCUDERO; TRILLO, 2017, p. 73). Essa perspectiva de análise da formação de professores evidencia que não basta investir na formação técnica dos professores. É necessário pensar e desenvolver essa formação valorizando os conhecimentos prévios dos futuros professores, oportunizando o acesso aos diferentes conhecimentos da profissão docente, bem como valorizando dinâmicas de formação alicerçadas na reflexão crítica, na colaboração, entre outros aspectos.

Denominamos dinâmicas da formação as diferentes experiências curriculares e extracurriculares que permeiam a formação de professores. Dentre essas experiências podemos citar: Estágios extracurriculares, curriculares e monitorias, lembrando que cada uma dessas experiências oportuniza aprendizagens e conhecimentos que ampliam a formação profissional. Com efeito, convém destacar que não analisaremos todas as experiências mencionadas, pois nosso interesse, neste estudo, é analisar a formação de professores, enfatizando o estágio supervisionado como espaço formativo que faculta aos futuros 
professores a produção de aprendizagens docentes e de conhecimentos sobre a profissão professor.

O estágio supervisionado, ao longo do tempo, tem sido revisitado, seja em relação ao formato, seja no que diz respeito aos seus objetivos e a sua carga horária, conforme as diferentes versões oficiais propostas para a formação inicial. Cabe esclarecer que entendemos o estágio supervisionado como um espaço formal de aprendizagens docentes, que necessita de um criterioso planejamento produzido com a efetiva participação da universidade e das escolas que constituem campo de estágio.

Pimenta e Lima (2017, p. 104) contribuem com estudos sobre o estágio supervisionado na formação de professores como contexto de aprendizagens docentes, destacando: “Aprender a profissão docente no decorrer do estágio supõe uma especial atenção as particularidades e interfaces da realidade escolar em sua contextualização na sociedade". A noção de estágio como uma das fontes de aprendizagem sobre a profissão professor implica na definição clara da identidade do estágio supervisionado e, consequentemente, implica no planejamento das atividades conforme explicitado como objetivos desse componente formativo.

O planejamento das ações do estágio, elaborado por meio das redes de relações entre universidade e escola denota a importância dessa parceria e, principalmente, realça o compromisso com essa importante atividade formativa. Zabalza (2014) trata sobre a formalização do estágio destacando a importância do planejamento desse componente da formação de professores, por meio de projetos abertos e flexíveis. Segundo o autor, planejar o estágio é uma forma de pensar a totalidade de ações a serem vivenciadas, supõe assumir compromissos, possibilita a avaliação do processo, explicita a natureza formativa da atividade e os diferentes papeis a serem assumidos por todos os envolvidos.

O planejamento da atividade de estágio supervisionado, em nossa concepção, tem muitas vantagens, dentre elas podemos destacar: requer aproximação entre universidade e escola campo de estágio, oportuniza a sistematização das experiências formativas, a partir de diagnóstico sobre a escola onde se desenvolverá o estágio, propicia a avaliação contínua das atividades desenvolvidas, possibilitando mudanças, caso seja necessário.

Planejar o estágio supervisionado exige, inicialmente, o estreitamento de vínculos entre universidade e escola, que pode ser tecido, inicialmente, pelos professores desse componente curricular de formação. A aproximação entre universidade e escola resulta na interação entre professores da universidade e professores da educação básica, bem como abre um importante diálogo entre os professores que atuam nesses contextos, que favorece o 
conhecimento da realidade dessas instituições e dá pistas para que a atividade de estágio atenda tanto os interesses das universidades, quanto interesses e necessidades das escolas.

A aproximação entre universidade e escola, para o planejamento das atividades de estágio, cria possibilidades para a inserção dos estagiários nas escolas sem que haja resistência por parte da escola e dos professores. As escolas e os professores têm apresentado resistência a aceitação e ao acompanhamento de estagiários, respaldando-se, entre outros, nos seguintes motivos: a atividade de estágio compromete a prática docente e o acompanhamento dos estagiários acontece de modo assistemático. Por que os professores e as escolas resistem ao acompanhamento de estagiários? O que pode ser feito para superar essa realidade?

As experiências que vivenciamos na condição de professora de estágio supervisionado nos revelaram a necessidade de revisitar a identidade dessa experiência formativa, tanto no âmbito da universidade, quanto no âmbito das escolas de educação básica. Na universidade, há no contexto do curso de Pedagogia o reconhecimento do de que o estágio supervisionado oportuniza aprender a profissão docente. Ocorre que a formação de professores nem sempre acontece nos Centro de Ciências da Educação e, em decorrência desse e de outros aspectos, o modo de pensar o estágio supervisionado subvaloriza as experiências que os futuros professores vivenciam por meio das atividades de estágio, evidenciando, em muitos casos, a negação do conhecimento profissional docente e, principalmente, a desvalorização do conhecimento pedagógico.

No contexto das escolas de ensino fundamental, locus de nossa atuação, percebemos que existem vários fatores que afetam o desenvolvimento dos estágios supervisionados. Dentre esses fatores, ganham realce a ausência de um planejamento de atividades, construído em parceria com as escolas e com os professores, o distanciamento universidade-escola e a falta de acompanhamento sistemático aos estagiários durante a permanência nas escolas. Os fatores mencionados comprometem a inserção de futuros professores nas atividades pedagógicas desenvolvidas nas escolas e nas salas de aula e se manifestam por meio da resistência de alguns professores diante da possibilidade de acompanhamento de estagiários, particularmente na regência de classe.

Ao refletirmos sobre a inserção de estagiários nas escolas reconhecemos que as interações entre os professores experientes e os futuros professores podem ser bastante promissoras. O estágio supervisionado é um dos canais para que essa interação aconteça e seja fértil como fonte de compartilhamento de conhecimentos e de experiências. Nóvoa (2009) entende que a formação de professores necessita acontecer dentro da profissão, ou seja, que os 
professores em formação possam participar efetivamente do que acontece nas escolas e nas salas de aula, convivendo com professores experientes, analisando as diferentes situações peculiares ao cotidiano da profissão.

Nessa convivência, que pode se efetivar por meio do estágio supervisionado, o autor pressupõe que os diferentes atores envolvidos podem refletir sobre diferentes aspectos da prática docente (por exemplo, sobre o insucesso escolar), analisar coletivamente as práticas desenvolvidas, comprometer-se com necessidades e anseios dos estudantes e ter abertura para mudanças. As proposições do autor sugerem, entre outros aspectos, o exercício da reflexão, o trabalho coletivo e que as propostas teóricas sejam produzidas no interior da profissão, explicitando a unidade teoria-prática. Tendo como referência as reflexões tecidas nesta seção estudo apresentamos na sequência uma análise sobre o estágio supervisionado, situando-o como espaço de experiências que forma.

\section{Estágio supervisionado na formação de professores: experiências que formam}

$\mathrm{Na}$ tessitura de nossas histórias como professora subsidiamos nossa prática docente na ideia do estágio supervisionado como experiência formadora, recorrendo aos estudos de Josso (2004, p. 39) que compreende a experiência formadora como propiciadora de “[...] uma aprendizagem que articula, hierarquicamente: saber-fazer e conhecimentos, funcionalidade e significações, técnica e valores num espaço-tempo que oferece a cada um a oportunidade de uma presença para si e para a situação [...]". Para essa pesquisadora as experiências são vivências particulares que, para assumirem o status de experiências formadoras, exigem o exercício reflexivo sobre o que foi vivido, observado e o que foi sentido.

É partindo do conceito de experiência formadora que explicitamos as vivências na disciplina estágio supervisionado, anos iniciais do ensino fundamental, no curso de Pedagogia, particularmente voltadas para inserção de futuros professores na escola, de modo que assumissem, sob o acompanhamento de professores experientes, a regência de classe. $\mathrm{O}$ ponto de partida para pensarmos a disciplina resultou dos seguintes questionamentos: Como tornar o estágio supervisionado uma experiência formadora? Que atividades contemplar para que os futuros professores pudessem refletir sobre seus percursos de formação e sobre as aprendizagens auferidas durante o estágio? Como fazer para que o estágio supervisionado se tornasse uma experiência significativa para a escola e seus professores? 
Esses questionamentos orientaram o processo de organização do estágio, que se deu por meio da formalização de um planejamento de atividades a serem desenvolvidas na universidade e na escola campo do estágio. Nas interações iniciais com os estudantes, futuros professores, identificamos que vivenciavam sentimentos diversos (medo, euforia e curiosidade). Medo de enfrentar o fracasso, de não obter sucesso na mediação didática e na gestão das interações na sala de aula. Medo também de não contar com o apoio e acompanhamento dos professores experientes. Euforia e curiosidade pela expectativa do encontro com as condições objetivas e subjetivas da profissão docente e pelas possibilidades de viver as dores e as delicias de ensinar-aprender.

Percebemos, então, que no desenvolvimento da disciplina poderíamos explorar a unidade teoria-prática, a escrita de si e a reflexão. No que concerne à unidade teoria-prática, pensamos em alternativas de leitura que possibilitassem os estagiários a fundamentarem suas reflexões e posicionamentos sobre a complexidade da profissão docente, sobre os professores e sobre suas práticas. Para tanto, propusemos leituras que contemplassem o processo de tornar-se professor, as singularidades da profissão docente (complexidade, as exigências postas aos professores e os conhecimentos profissionais docentes), o ciclo de vida dos professores e a reflexão na prática docente. As leituras permearam todo o desenvolvimento do estágio e serviram de base para análise e reflexão sobre/nas práticas, conforme será explicitado na sequência deste texto.

A escrita de si foi vivenciada com atividades de escrita autobiográfica. Essa modalidade de escrita apresentou potencial significativo para o desenvolvimento da reflexividade, para o autoconhecimento e para tomada de consciência sobre a implicação dos sujeitos em suas práticas e em seus percursos. A escrita autobiográfica “[...] congrega e entrelaça experiências muito diversas, é possível interrogar-nos sobre escolhas, inércias e as dinâmicas" (JOSSO, 2004, p. 41). Escrever sobre si e sobre as experiências vivenciadas exigiu o desenvolvimento da reflexão e implicou na revisitação dos percursos formativos, notadamente sobre como os futuros professores assumiram as rédeas de sua formação e sobre as aprendizagens produzidas.

Com a explicitação dos aspectos referentes à unidade teoria-prática, à escrita de si e à reflexão, cabe-nos descrever de forma detalhada as atividades compartilhadas no estágio supervisionado. Na organização da disciplina estabelecemos diferentes tempos de formação: tempo na universidade e tempo na escola campo de ocorrência do estágio supervisionado. $\mathrm{O}$ tempo na universidade foi menor que o tempo na escola e foi idealizado para realizarmos 
rodas de conversa, que aconteciam quinzenalmente com o objetivo de refletirmos coletivamente sobre nossas experiências no estágio.

O tempo da escola teve como ponto de partida a definição do contexto de ocorrência do estágio supervisionado. Para essa definição estabelecemos os seguintes critérios: realizar o estágio supervisionado em uma escola reconhecida como contexto de práticas bem sucedidas e selecionar uma escola de fácil acesso para os estudantes. O que nos levou a optar por uma escola bem sucedida? Durante o planejamento das atividades do estágio, os estudantes revelaram desencantamento com a escola pública e descrédito em suas potencialidades no que se refere ao processo de ensino e aprendizagem das crianças.

Estabelecidos os critérios para definição da escola campo de estágio, procuramos dialogar com gestores e professores de uma escola, com o perfil esperado, para saber da possibilidade de estabelecermos parcerias entre universidade e escola. Nesta oportunidade, apresentamos os objetivos e a caracterização das atividades da disciplina, explicitando sobre a flexibilidade da proposta para que gestores e professores pudessem participar do planejamento das ações. Analisamos os diferentes papeis, responsabilidades dos envolvidos e a proposta de cronograma das atividades, assumindo coletivamente o compromisso de diálogo permanente e de acompanhar sistematicamente as atividades.

Tomando como suporte o pensamento de Nóvoa (2019), no diálogo com a escola realçamos a importância do estágio supervisionado na formação de professores, por entender que as experiências vivenciadas podem ser decisivas no percurso profissional dos futuros professores. O estágio supervisionado pode ser considerado como fase de iniciação à docência, como momento singular de experiência profissional, de encontro com a realidade das escolas, com os professores experientes e com suas práticas.

Razão por que, “[...] devemos insistir na responsabilidade das direções das escolas e dos professores mais experientes quanto ao acolhimento e acompanhamento dos seus jovens colegas" (NÓVOA, 2019, p. 200). A despeito do reconhecimento dessas responsabilidades, a universidade também precisa oferecer às escolas uma contrapartida, levando em conta suas demandas e as necessidades de professores e de alunos, para fortalecimento de laços e de parcerias que podem ser produtivas para todos os envolvidos.

Considerando as condições negociadas com a escola de ensino fundamental para realização do estágio supervisionado, providenciamos o encaminhamento dos estudantes de Pedagogia para o encontro com a instituição escolar, com os professores e com a prática docente. "E esse encontro inicial com o mundo profissional abre portas para outros múltiplos 
encontros" (ZABALZA, 2014, p. 145). Conforme mencionado pelo autor, o estágio faculta aos futuros professores a vivência de diferentes encontros (com a realidade da escola e do ensino, consigo mesmo, com seus pares, com professores experientes, entre outros). Esses encontros potencializam aprendizagens e conhecimentos significativos no processo de formação de professores.

O encontro dos futuros professores com a realidade da escola e do ensino, via estágio supervisionado, iniciou com atividades de observação, com o objetivo de obter informações para conhecimento da realidade sociocultural onde a escola está inserida, sobre os alunos da escola e para estreitar relações entre estagiários e professores experientes. Essa etapa resulta em conhecimentos iniciais sobre o contexto, sobre a escola (suas práticas e suas rotinas) e sobre os alunos. "Quanto mais intensa for esta, melhor rendimento propiciará o estágio. Desta maneira, o saber sobre se completa com o saber como, aspecto-chave na pretendida formação por competências" (ZABALZA, 2014, 117).

Durante a observação negociamos a lotação dos estagiários para a regência de classe e encaminhamos o planejamento das aulas, contando com a colaboração da equipe administrativa da escola (direção e coordenação pedagógica) e dos professores. Para realização do planejamento os estagiários contaram com material disponibilizado pela escola e foram inseridos no planejamento realizado na instituição escolar, que se caracterizava como momento de reflexão e de análise das práticas docentes e dos limites e das possibilidades dos alunos, envolvendo coletivamente os professores. Em todas as situações vivenciadas pelos futuros professores, no âmbito da escola contexto de ocorrência do estágio, interagíamos com eles e com os professores experientes, buscando colaborar com uma mediação didática qualificada, pois sabemos que a inserção dos estagiários na sala de aula afeta a dinâmica da sala de aula e do processo de ensino e aprendizagem.

A propósito, as experiências dos estagiários foram registradas em diários da prática. Os diários são documentos pessoais de natureza autobiográfica, que expressam as ações cotidianas desenvolvidas por seus autores, veiculam suas concepções e seus conhecimentos. $\mathrm{O}$ conteúdo dos diários pode apresentar descrições, reflexões e análises sobre as práticas dos narradores. A proposta de escrita do diário da prática, no desenvolvimento do estágio supervisionado, teve como principal objetivo o registro das situações cotidianas vivenciadas pelos estagiários, para que pudessem refletir a respeito de suas práticas, de seus dilemas e de seus aprendizados no encontro com a sala de aula. 
De modo geral, podemos caracterizar os diários escritos pelos estagiários como “[...] descrição de tarefas: são os diários em que o foco principal de atenção se centra nas tarefas que professores e alunos realizam na sala de aula" (ZABALZA, 1997, 111). Apesar da natureza descritiva, essa modalidade de diário, no contexto da formação e do estágio supervisionado, oportuniza o desenvolvimento da reflexão e constitui importante instrumento formativo. Como é possível perceber, a escrita dos diários decorreu de processos de reflexão sobre as experiências vividas, sobre as decisões tomadas, envolvendo seus autores em diálogos consigo mesmos para análise das práticas desenvolvidas e de suas implicações na formação e no estágio supervisionado. A escrita dos diários é importante, também, para o conhecimento de si e para ampliar a consciência sobre a prática.

Além da escrita dos diários, para registro das atividades, planejamos a realização de rodas de conversa, que aconteciam quinzenalmente na universidade para que pudéssemos refletir coletivamente a respeito do desenvolvimento do estágio. As rodas de conversa propiciam o diálogo, o compartilhamento de experiências e possibilitam diferentes relações (consigo, com os outros, com as práticas e com o conhecimento). Na acepção de Charlot (2000, p. 48): “[...] toda relação consigo mesmo é relação com o outro. Toda relação com o outro é relação consigo mesmo. E essa dupla relação [...] é relação entre eu e o outro em um mundo que partilhamos". As rodas de conversa, portanto, protagonizam interações singulares que constituem espaços para reelaboração do vivido e de conhecimentos.

As reflexões tecidas nas rodas de conversa tiveram como ponto de partida os registros produzidos nos diários. Esses registros contemplavam as descrições de atividades, que eram socializados nas rodas de conversa e analisados à luz do conhecimento teórico, de modo que os futuros professores pudessem compreender as teorias subjacentes a suas práticas, na perspectiva de que pudessem, caso necessário, reelaborar suas práticas. Nos momentos de reflexão coletiva emergiram questões referentes às interações entre estagiários, alunos e professores experientes, às dificuldades enfrentadas e à medição didática.

A respeito das interações entre estagiários e alunos, ressaltamos a preocupação dos futuros professores com o controle de turma, com a indisciplina, de modo especial, e com a necessidade de tomar decisões no transcurso das ações. Quanto às interações com os professores experientes, identificamos por parte da escola significativa disposição para colaborar com a formação dos estagiários, materializada nas orientações do planejamento e da mediação didática. Esses aspectos foram objeto de reflexão coletiva, que indicou a necessidade de reconstrução de algumas práticas, tanto em relação à gestão das interações em 
sala de aula, quanto em relação a autonomia dos estagiários na regência de classe (para evitar a sobrecarga dos professores experientes).

No tocante à mediação didática, bem como sobre as dificuldades inerentes a ela, as reflexões socializadas indicaram que para ensinar é necessário articular o conhecimento do conteúdo a outros conhecimentos que compõem a base da profissão docente. Neste caso, identificamos estagiários que reconheceram não ter domínio do conteúdo a ser ensinado, provocando, no contexto da escola campo do estágio, a mobilização da equipe pedagógica no sentido de prover "situações de formação em serviço" para que aprendessem. A situação ilustrada nos levou a refletir a respeito da necessidade de autoformação e do compromisso pessoal de cada estagiário.

Diários da prática e rodas de conversa constituíram dois importantes dispositivos de acompanhamento das práticas e de reflexão no âmbito do estágio supervisionado. Por meio dos diários, os estagiários produziram reflexões individuais sobre si e sobre suas experiências. Nas rodas de conversa, com o recurso da escrita nos diários e com a rememoração do que foi vivido na escola e na sala de aula, os estagiários compartilharam reflexões, socializaram experiências e pensaram possibilidades para a problemas identificados. Trata-se de reconhecer a reflexão como fundamento para o autoconhecimento, para análise crítica das práticas. "Reflete-se sobre algo, neste caso, a experiência que se está vivenciando, o que está fazendo. E, portanto, a riqueza da reflexão dependerá, em geral, da riqueza da própria experiência" (ZABALZA, 2014, p. 188).

Como percebemos, o estágio supervisionado tem potencial formativo, pode ser considerado como importante experiência formadora se os seus percursos forem sistematicamente planejados, se as ações forem acompanhadas pelas instituições formadoras. No desenvolvimento do estágio supervisionado, universidade e escola são parceiras na complexa tarefa de formar professores, todavia essa parceria requer contrapartidas " [...] para facilitar a mobilidade de nossos estudantes e, se necessário, compensar a dedicação dos profissionais que atendem aos nossos alunos nos centros de práticas [...]". Com efeito, sem uma parceria efetiva entre universidade e escola as ações do estágio supervisionado podem limitar-se à condição de atividade burocrática.

\section{À guisa de conclusão}

O estágio supervisionado integra a formação de professores, constitui fonte de aprendizagens sobre a profissão docente, portanto, reverbera como experiência formadora. 
"Cabe-lhe desenvolver atividades que possibilitem o conhecimento, a análise, a reflexão do trabalho docente, das ações docentes, nas instituições, a fim de compreendê-las em sua historicidade [...]” (PIMENTA; LIMA, 2017, p. 47). O estágio supervisionado, na formação inicial de professores, transcende à mera atividade burocrática, pois tem propósitos formativos voltados para as peculiaridades da profissão docente, considerando aspectos objetivos e subjetivos dessa profissão.

O que esperamos, com o estágio supervisionado, é que a participação dos futuros professores nas experiências de estágio possa enriquecer suas vivências com a realidade das escolas e, também, com as rotinas docentes no cotidiano de suas práticas para que percebam as demandas dessa prática e, também, para que compreendam as condições concretas de desenvolvimento do trabalho docente. O essencial é que possam analisar criticamente a realidade da profissão e das práticas docentes, o que pode acontecer se o estágio supervisionado facultar as condições para a reflexão crítica e para a investigação sobre essa realidade.

Granjeiro (2008, p. 10) o estágio tem importante papel na formação de professores e em suas práticas. Conforme a autora, o conhecimento da realidade da profissão, "[...] onde desempenhará sua escolha profissional, e refletir sobre o que se encontra na prática, abrindo espaço para a proposição de soluções fundamentadas na teoria é, sem dúvida, um grande estímulo à capacidade crítica e criativa do estagiário”. Conhecer a realidade das escolas e das práticas docentes não se limita a observar apenas o que fazem os professores, mas demanda analisar o contexto social onde essas escolas estão inseridas, conhecer as singularidades da clientela que atende e refletir sobre as condições de desenvolvimento da profissão docente.

Pessoa (2011, p. 108), ao abordar o aprender a ensinar, sugere que os futuros professores necessitam aprender a pensar, a analisar a realidade do ensino e da aprendizagem, estabelecendo a pertinente unidade teoria-prática. Defende, neste sentido, que: "Pensar como professor é pensar de forma reflexiva num diálogo ou conversa com a prática, ou com diversas situações educativas, construindo sentidos e significados, e, assim, conhecimento no sentido de uma ação competente". Analisando as ideias da autora vislumbramos as possibilidades de desenvolvimento da reflexão no estágio supervisionado, com o suporte das narrativas escritas (diários da prática, por exemplo) e das narrativas orais (rodas de conversa), consubstanciadas na unidade teoria-prática.

As narrativas no contexto do estágio supervisionado registram as experiências formadoras, aquelas que foram significativas na produção das identidades dos futuros 
professores e em suas aprendizagens sobre a profissão docente. As escritas das narrativas demarcam, de modo especial, a intensidade das experiências vividas e compartilhadas no estágio, explicitando como os sujeitos envolvidos foram afetados por elas e, também, como essas experiências afetaram suas subjetividades e suas identidades.

Considerando que apresentamos como objetivo do estudo analisar a importância do estágio supervisionado na formação inicial de professores, como experiência formadora, precisamos esclarecer que essa fazer do estágio uma experiência formadora pode se resumir a atividade burocrática, exige um planejamento compartilhado, a parceria universidade/escola, o acompanhamento sistemático aos estagiários, a reflexão sobre as experiências vividas e a abertura para a reelaboração de práticas e de modos de ser.

\section{REFERÊNCIAS}

CHARLOT, Bernard. Da relação com o saber: elementos para uma teoria. Porto Alegre, RS: Artmed, 2000.

ESCUDERO, Juan M.; TRILLO, Felipe. O desenvolvimento profissional dos professores: crise do currículo, das práticas, dos efeitos da formação docente? In: FLORES, Maria Assunção; MOREIRA, Maria Alfredo; OLIVEIRA, Lia Raquel. Desafios curriculares e pedagógicos na formação de professores. Ramada, PT: Edições Pedago, LDA; Santo Tirso, PT: De Facto Editores, 2017.

FORMOSINHO, João. A academização da formação de professores. In: FORMOSINHO (Coord.). Formação de professores e acção docente. Porto, PT: Porto Editora, 2009.

GRANGEIRO, Manuela Fonseca. O estágio na formação tecnológica. In: XIV ENDIPE Encontro Nacional de Didática e Prática de Ensino. Anais do XIV ENDIPE, 2008.

IMBERNÓN, Francisco. Formação docente e profissional: formar-se para a mudança e a incerteza. São Paulo, SP: Cortez, 2009.

JOSSO, Marie-Christine. Experiências de vida e formação. São Paulo, SP: Cortez, 2004.

MOREIRA, Maria Alfredo; FLORES, Maria Assunção; OLIVEIRA, Lia Raquel. Desafios curriculares e pedagógicos na formação de professores. Ramada, PT: Edições Pedago, LDA; Santo Tirso, PT: De Facto Editores, 2017.

NÓVOA, António. Professores: imagens do futuro presente. Lisboa, PT: EDUCA, 2009.

NÓVOA, António. Entre a formação e a profissão: ensaio sobre o modo como nos tornamos professores. Currículo sem Fronteiras, v. 19, n. 1, p. 198-208, jan./abr. 2019. 
PESSOA, Maria Teresa. A vida nas escolas: casos para a formação de professores. Coimbra, PT: Imprensa da Universidade de Coimbra, 2011.

PIMENTA, Selma Garrido; LIMA, Maria do Socorro Lucena. Estágio e docência. São Paulo, SP: Cortez, 2017.

PINEAU, Gaston. A autoformação no decurso da vida: entre a hetero e a ecoformação. In: NÓVOA, António; FINGER, Mathias. O método autobiográfico a formação. Natal, RN: EDUFRN; São Paulo, SP: Paulos, 2019.

SCHEIBE, Leda. Revista Retratos da Escola, Brasília, v. 2, n. 2-3, p. 41-53, jan./dez. 2008.

ZABALZA, Miguel A. O estágio e as práticas em contextos profissionais na formação. São Paulo, SP: Cortez, 2014.

\section{SOBRE A AUTORA:}

\section{Antonia Edna Brito}

Doutorado em Educação, Universidade Federal do Rio Grande do Norte (UFRN). Professora do da Universidade Federal do Piauí (UFPI), no Departamento de Métodos e Técnicas de Ensino e no Programa de Pós-Graduação em Educação/PPGEd/UFPI. Coordenadora do Núcleo de Estudos e Pesquisas sobre Formação e Profissionalização docente em Pedagogia/NUPPEd. E-mail: antonedna@ hotmail.com

\section{(iD https://orcid.org/0000-0002-0064-6501}

Recebido em: 14 de abril de 2020 